\title{
Effect of Different Calcination Duration on Physicochemical Properties of Vanadium Phosphate Catalysts
}

\author{
YUN HIN TAUFIQ-YAP ${ }^{* 1,2}$, HWEI VOON LEE ${ }^{1}$, YIN CHANG WONG ${ }^{1}$, KOK LEONG $^{1}$ \\ THEAM $^{1,2}$ and WEN JIUNN TANG ${ }^{1}$
}

${ }^{1}$ Centre of Excellence for Catalysis Science and Technology, ${ }^{2}$ Department of Chemistry, Faculty of Science, Universiti Putra Malaysia. 43400 UPM Serdang, Selangor, Malaysia.

yap@science.upm.edu.my

Received 31 October 2011; Accepted 02 January 2012

\begin{abstract}
Vanadium phosphate catalysts have been prepared by calcining $\mathrm{VOHPO}_{4} \cdot 0.5 \mathrm{H}_{2} \mathrm{O}$ which were prepared via two methods i.e. organic (VPO method) and dihydrate (VPD method) routes for different duration under anaerobic atmosphere. Increasing the calcinations duration led to a decrease in total surface area. It is also promote the formation of $\mathrm{V}^{5+}$ phase in the catalysts. Scanning electron microscopy clearly revealed that the morphologies of all catalysts composed of plate-like crystallites that were arranged into the characteristic of rosette cluster. However, by increasing the pretreatment duration in an inert environment, the rosette-shape of the clusters which normally obtained in reaction condition was collapsed. Prolong the duration of $\mathrm{N}_{2}$ calcination also resulted in an increment in the amount of oxygen desorbed (from $\mathrm{O}_{2}$-TPD) and removed (obtained from $\mathrm{H}_{2}$-TPR).
\end{abstract}

Keywords: vanadium phosphate; oxygen; SEM; TPD; TPR.

\section{Introduction}

Vanadium phosphorus oxide has been extensively applied in the production of maleic anhydride from $n$-butane. All studies have focused on two specific phases, i.e. $\mathrm{VOHPO}_{4} \cdot 0.5 \mathrm{H}_{2} \mathrm{O}$ and $(\mathrm{VO})_{2} \mathrm{P}_{2} \mathrm{O}_{7}$. The catalyst precursor $\mathrm{VOHPO}_{4} \cdot 0.5 \mathrm{H}_{2} \mathrm{O}$, which was subsequently transformed under reaction conditions to gave the vanadyl pyrophosphate, $(\mathrm{VO})_{2} \mathrm{P}_{2} \mathrm{O}_{7}$, which consider to be the active component of vanadium phosphate catalyst ${ }^{1}$. The degree of crystallinity (morphology, presence of stacking faults, preferential exposure of crystalline planes, surface area) of the precursor phase has a considerable effect on the structural evolution during heating and the final properties of the $(\mathrm{VO})_{2} \mathrm{P}_{2} \mathrm{O}_{7}$. The transformation of the precursor to $(\mathrm{VO})_{2} \mathrm{P}_{2} \mathrm{O}_{7}$ involves two water-loss steps, the first associated with water of crystallization and the second with the transformation of hydrogen phosphate to pyrophosphate. The two transformations can occur simultaneously, depending on the nature of the precursor phase and the heat treatment ${ }^{2}$. When oxygen is present in the atmosphere, there is also oxidation which leading to various possible $\mathrm{V}^{5+}$ phosphate phases $\left(\alpha_{\mathrm{I}}, \alpha_{\mathrm{II}}, \beta, \gamma, \delta\right)$ again depending on both the nature of the precursor phase and the conditions 
of the heat treatment. Thus, there are a broad range of possibilities in terms of catalyst composition after the heat treatment step, with identification of some of the phases also being difficult ${ }^{3}$.

Our group has been investigated the effect of the different calcinations duration of $n$ butane/air pretreatment on the vanadium phosphate catalysts synthesized via organic method $^{4,5}$. In this paper, we would like to study the effect of different calcination duration on the vanadium phosphate catalysts prepared via $\mathrm{VPO}^{6,7}$ and $\mathrm{VPD}^{6,8,9}$ method. The precursors were calcined in an inert environment to produce catalysts which mainly consist of $(\mathrm{VO})_{2} \mathrm{P}_{2} \mathrm{O}_{7}$ phase.

\section{Experimental}

\section{Preparation of Catalysts via VPO Method}

The precursor of the promoted catalyst, $\mathrm{VOHPO}_{4} \cdot 0.5 \mathrm{H}_{2} \mathrm{O}$ was prepared by reacting $8.0 \mathrm{~g}$ of $\mathrm{V}_{2} \mathrm{O}_{5}, 48 \mathrm{ml}$ of isobutyl alcohol and $32 \mathrm{ml}$ of benzyl alcohol. The mixture was reflux for $7 \mathrm{~h}$ at $393 \mathrm{~K}$ with constant stirring. The solution was then cooled down and left stirring overnight. Then $10.2 \mathrm{ml}$ of $o-\mathrm{H}_{3} \mathrm{PO}_{4}(85 \%)$ was then added in to the solution to obtain the desired $\mathrm{P}: \mathrm{V}$ atomic ratio. The mixture was further refluxed for $3 \mathrm{~h}$ at $393 \mathrm{~K}$ with constant stirring. The solid was recovered by centrifuge, washed sparingly with acetone, followed by water and dried in oven at $373 \mathrm{~K}$ for $24 \mathrm{~h}$, and then identified by XRD as $\mathrm{VOHPO}_{4} \cdot 0.5 \mathrm{H}_{2} \mathrm{O}$. The precursors were calcined at the temperature $733 \mathrm{~K}$ for 6 hour, 24 hour and 48 hour in a reaction flow of nitrogen gas. The three catalysts obtained were denoted as VPO6, VPO24 and VPO48, respectively.

\section{Preparation of Catalysts via VPD Method}

The preparation of precursor involves a two-step procedure based on $\mathrm{VOPO}_{4} \cdot 2 \mathrm{H}_{2} \mathrm{O}$ as an intermediate before obtaining the precursor, VOHPO ${ }_{4} \cdot 0.5 \mathrm{H}_{2} \mathrm{O}$. The $\mathrm{VOPO}_{4} \cdot 2 \mathrm{H}_{2} \mathrm{O}$ was prepared by reacting $12.0 \mathrm{~g}$ of $\mathrm{V}_{2} \mathrm{O}_{5}$ with $57.4 \mathrm{ml}$ of $o-\mathrm{H}_{3} \mathrm{PO}_{4}(85 \%)$ in $288 \mathrm{ml}$ water under reflux with continuous stirring for $24 \mathrm{~h}$. The yellow solid was recovered by centrifuge, washed sparingly with acetone, followed by water and dried in oven at $373 \mathrm{~K}$ for $24 \mathrm{~h}$, and then identified by XRD as VOPO $\cdot 2 \mathrm{H}_{2} \mathrm{O}$. Then $4.0 \mathrm{~g}$ of $\mathrm{VOPO}_{4} \cdot 2 \mathrm{H}_{2} \mathrm{O}$ was refluxed with 80 $\mathrm{ml}$ of isobutyl alcohol for $21 \mathrm{~h}$. The solid was recovered by centrifuge, washed sparingly with acetone, followed by water and dried in oven at $373 \mathrm{~K}$ for $24 \mathrm{~h}$, and then identified by $\mathrm{XRD}$ as $\mathrm{VOHPO}_{4} \cdot 0.5 \mathrm{H}_{2} \mathrm{O}$. The precursors were calcined at the temperature $673 \mathrm{~K}$ for 6,24 and $75 \mathrm{~h}$ in a reaction flow of nitrogen gas. The three catalysts obtained were denoted as VPD6, VPD24 and VPD75, respectively.

\section{Catalysts Characterization}

The x-ray diffraction (XRD) analyses were carried out using Shimadzu diffractometer model XRD-6000 employing $\mathrm{CuK} \alpha$ radiation to generate diffraction patterns from powder crystalline samples at ambient temperature.

Scanning electron microscopy (SEM) analyses were carried out using a JEOL JSM6400 electron microscope.

The total surface area of the catalysts was measured by Brunauer-Emmett-Teller (BET) method by using nitrogen adsorption-desorption at $77 \mathrm{~K}$. This was done by using a ThermoFinnigan Sorptomatic 1990 instrument.

The average oxidation states of vanadium in all the samples were determined by the method described by Niwa and Murakami ${ }^{10}$.

The bulk chemical composition was determined by using a sequential scanning inductively coupled plasma-atomic emission spectrometer (ICP-AES) Perkin Elmer Emission Spectrometer model Optima 2000 DV. 
Temperature-programmed reduction in $\mathrm{H}_{2} / \mathrm{Ar}\left(\mathrm{H}_{2}-\mathrm{TPR}\right)$ and Temperature-programmed desorption of oxygen $\left(\mathrm{O}_{2}\right.$-TPD) experiments were performed using a ThermoFinnigan TPD/R/O 1100 apparatus utilising a thermal conductivity detector (TCD).

\section{Results and Discussion}

$X$-ray diffraction $(X R D)$

The XRD patterns of catalysts are shown in Figure 1. These catalysts gave only the characteristic reflections of $(\mathrm{VO})_{2} \mathrm{P}_{2} \mathrm{O}_{7}$ with peaks observed at $2 \theta=22.9^{\circ}, 28.5^{\circ}$ and $30.0^{\circ}$ which are corresponding to the reflection of (020), (024) and (221) planes, respectively. It is general believed that $(\mathrm{VO})_{2} \mathrm{P}_{2} \mathrm{O}_{7}$ is the active phase of VPO catalysts and the active crystal plane for selective oxidation of $n$-butane is the (020) plane $^{11}$. Interestingly, the catalysts synthesized via VPD method shows higher crystalline structure as the calcinations duration increased. VPD6 show the lowest crystalline structure, which indicated by the low intensity of the peak. This may due the insufficient calcination time for the precursor transform into $(\mathrm{VO})_{2} \mathrm{P}_{2} \mathrm{O}_{7}$ phase. Some researchers reported that the precursor first transforms into an amorphous phase ${ }^{12,13}$, which can be further dehydrated to crystalline $(\mathrm{VO})_{2} \mathrm{P}_{2} \mathrm{O}_{7}$.

The parameter which used to determine the degree of structural disorder of the VPO catalysts is the ratio of intensities of (020) and (204) reflections ${ }^{14}$. The different calcinations duration would affect the structural disorder of the VPD catalysts, because the ratio of intensities of the (020) and (204) reflections for VPD24 (0.83) and VPD75 (0.84) were lower than the VPD6 (1.38).

\section{BET Surface Area Measurement and Chemical Analysis}

Table 1 shows the experimental data on the $\mathrm{P} / \mathrm{V}$ ratio, BET surface area and the percentage of $\mathrm{V}^{4+}$ and $\mathrm{V}^{5+}$ presence in the catalysts. Chemical analysis using ICP shows that the $\mathrm{P} / \mathrm{V}$ ratio for all catalysts was in the optimal atomic ratio of $\mathrm{P} / \mathrm{V}$ in the range of $1.0-1.2^{15}$. The BET surface area for VPO6, VPO24 and VPO48 catalysts are 11, 10 and $7 \mathrm{~m}^{2} \mathrm{~g}^{-1}$, respectively. Raising the calcination time decreased the surface area. These results were in contrast with our previous work where the precursors were calcined in the reactant mixture of $n$-butane in air $^{4}$. The BET surface area for VPD6, VPD24 and VPD75 catalysts are 9,6 and $4 \mathrm{~m}^{2} \mathrm{~g}^{-1}$ which is lower than the organic prepared catalyst. A slight reduction in the surface area with a longer calcination duration may probably due to the fact that less platelets per cluster catalyst are formed. These values are also lower than those reported earlier16-20. The average vanadium oxidation number of the catalysts with longer calcination time was found higher compared to the catalysts with shorter calcination time. Both VPO6 and VPD6 have an average oxidation number of 4.00 and increased to 4.09, 4.08, 4.08 and 4.29 for VPO24, VPO48, VPD24 and VPD75, respectively.

\section{Scanning Electron Microscopy (SEM)}

Figure 3 show the surface morphologies of the catalysts with different calcination time. The structure of all catalysts were consist of plate like platelets which are arranged into the rosetteshape clusters ${ }^{4,21,22}$. However, the amounts of these characteristic rosette-shape agglomerates are different in all catalysts. VPO6 catalyst possesses more uniform rosette-type clusters than VPO24 and VPO48 catalysts. This should be the reason for the higher surface area of VPO6 compared to VPO24 and VPO48. There appeared to be a consistency whereby the amount of these rosette-type agglomerates decreased with increasing the calcinations time for the catalysts prepared by using VPO method. 


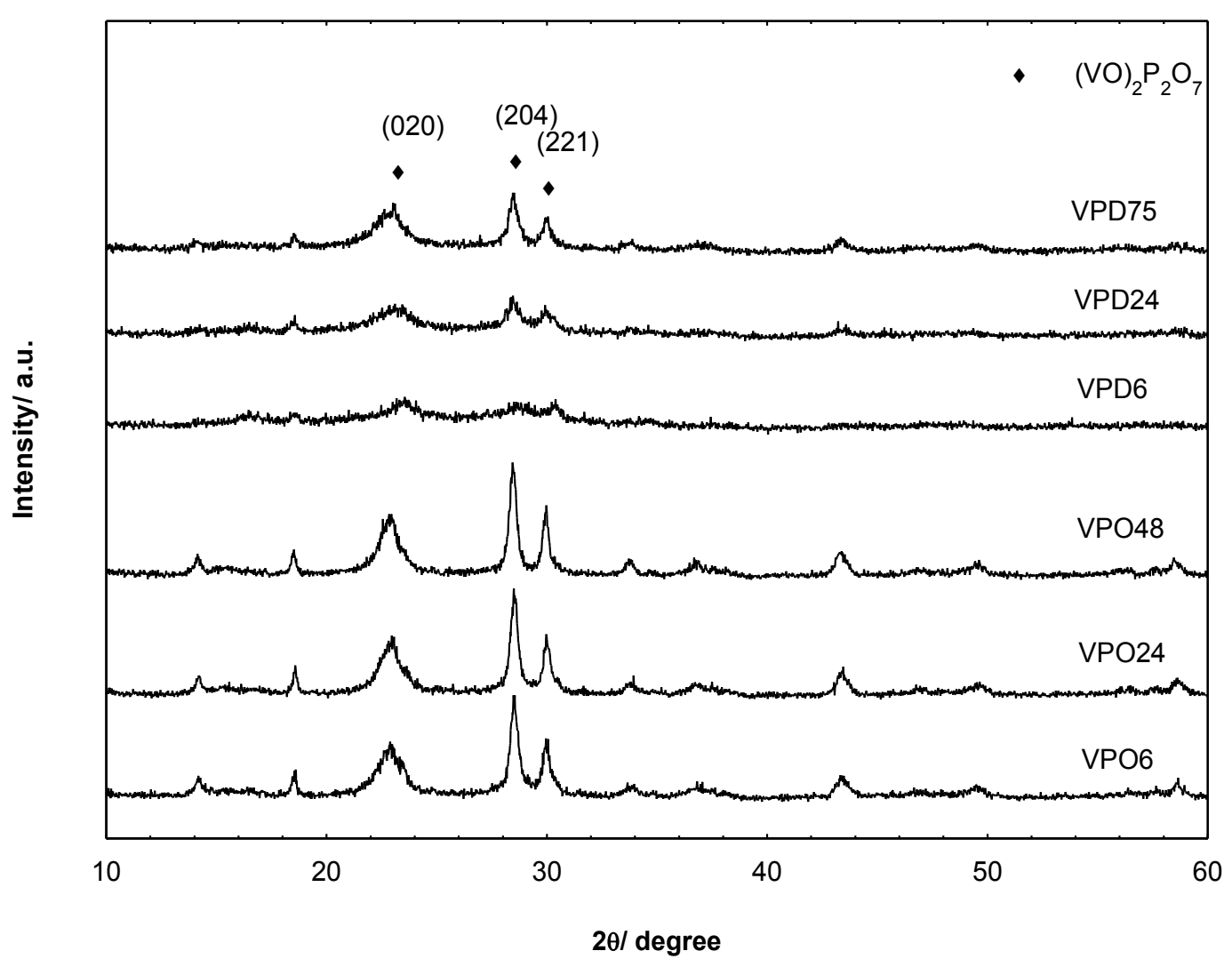

Figure 1. X-ray diffraction patterns of catalysts.

Comparison of the VPD6, VPD24 and VPD75 SEM images revealed that the catalyst which had been calcined for the longest duration, i.e. VPD75, appeared to have less prominent rosette-shape clusters and the structure startd collapse as compared to its less calcined counterparts. This is in agreement with the results obtained from BET surface area measurements, i.e. the surface area of VPD6 is higher than the samples with longer calcination time.

\section{Temperature-programmed Desorption of $\mathrm{O}_{2}\left(\mathrm{O}_{2}-\mathrm{TPD}\right)$}

Figure 3 show the TPD profiles of the catalysts. There was no desorption peak appeared at any temperature for VPO48 catalyst as compared to others catalysts. This result suggested that the oxygen species of VPO48 is likely to be less labile and reactive among the catalysts. VPO6 and VPO24 catalysts gave only one peak maximum at $963 \mathrm{~K}$ and $811 \mathrm{~K}$, respectively. As shown in Table 2, the amount of oxygen desorbed from VPO6 is $3.55 \times 10^{19}$ atom $\mathrm{g}^{-1}$. Interestingly, VPO24 gave higher amount of oxygen desorbed from the lattice i.e. $19.39 \times$ $10^{19}$ atom $\mathrm{g}^{-1}$. The significant higher amount of oxygen desorbed form VPO24 may possibly due to the lower desorption peak temperature which contributed to a lower desorption activation energy required for removal of more oxygen atoms from the lattice. 

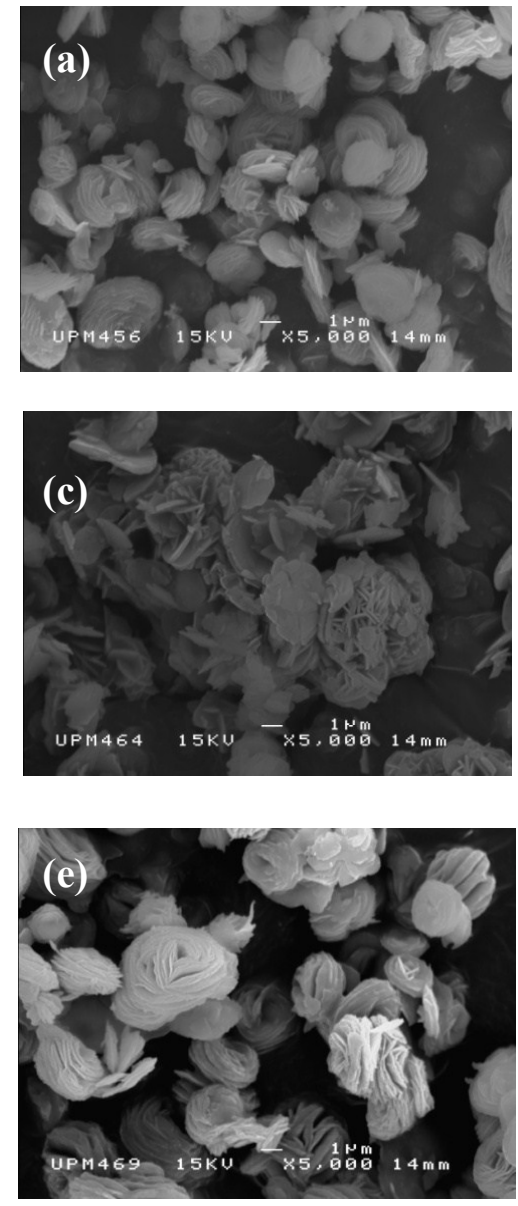
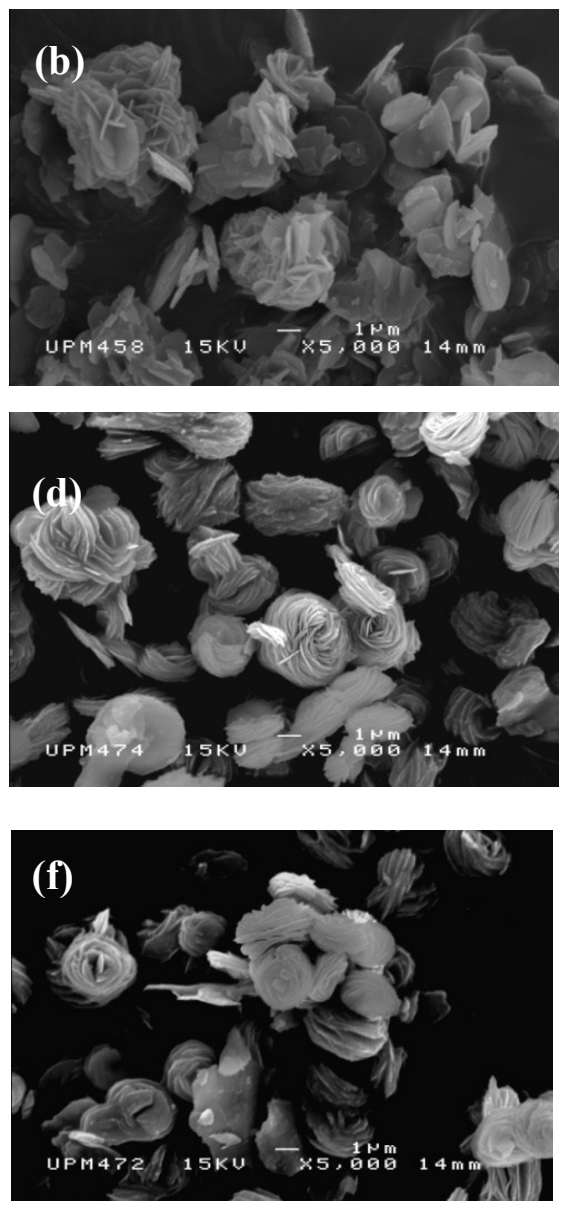

Figure 2. SEM micrographs for (a) VPO6, (b) VPO24, (c) VPO48, (d) VPD6, (e) VPD24 and (f) VPD75.

The amount of oxygen desorbed for VPD6, VPD24 and VPD75 are $16.86 \times 10^{19}, 13.25$ $\times 10^{19}$ and $31.92 \times 10^{19}$ atom $\mathrm{g}^{-1}$, respectively. VPD75 possess the highest amount of oxygen desorbed suggested that this catalyst may possibly favour a higher selectivity.

Table 1. Surface area, bulk composition, average oxidation states and percentage of $\mathrm{V}^{4+}$ and $\mathrm{V}^{5+}$ oxidation states present in catalysts.

\begin{tabular}{llllll}
\hline \multirow{2}{*}{ Catalysts } & \multirow{2}{*}{ Surface area $\left(\mathrm{m}^{2} \mathrm{~g}^{-1}\right)$} & $\begin{array}{l}\mathrm{P} / \mathrm{V} \text { Atomic } \\
\text { Ratio }\end{array}$ & \multicolumn{3}{l}{ Oxidation States of Vanadium } \\
\cline { 4 - 6 } & & 1.1 & $\mathrm{~V}^{4+}(\%)$ & $\mathrm{V}^{5+}(\%)$ & Average \\
\hline VPO6 & 11 & 1.1 & 100 & 0 & 4.00 \\
VPO24 & 10 & 1.0 & 91 & 9 & 4.09 \\
VPO48 & 7 & 1.1 & 92 & 8 & 4.08 \\
VPD6 & 9 & 1.0 & 100 & 0 & 4.00 \\
VPD24 & 6 & 1.0 & 92 & 8 & 4.08 \\
VPD75 & 4 & & 71 & 29 & 4.29 \\
\hline
\end{tabular}




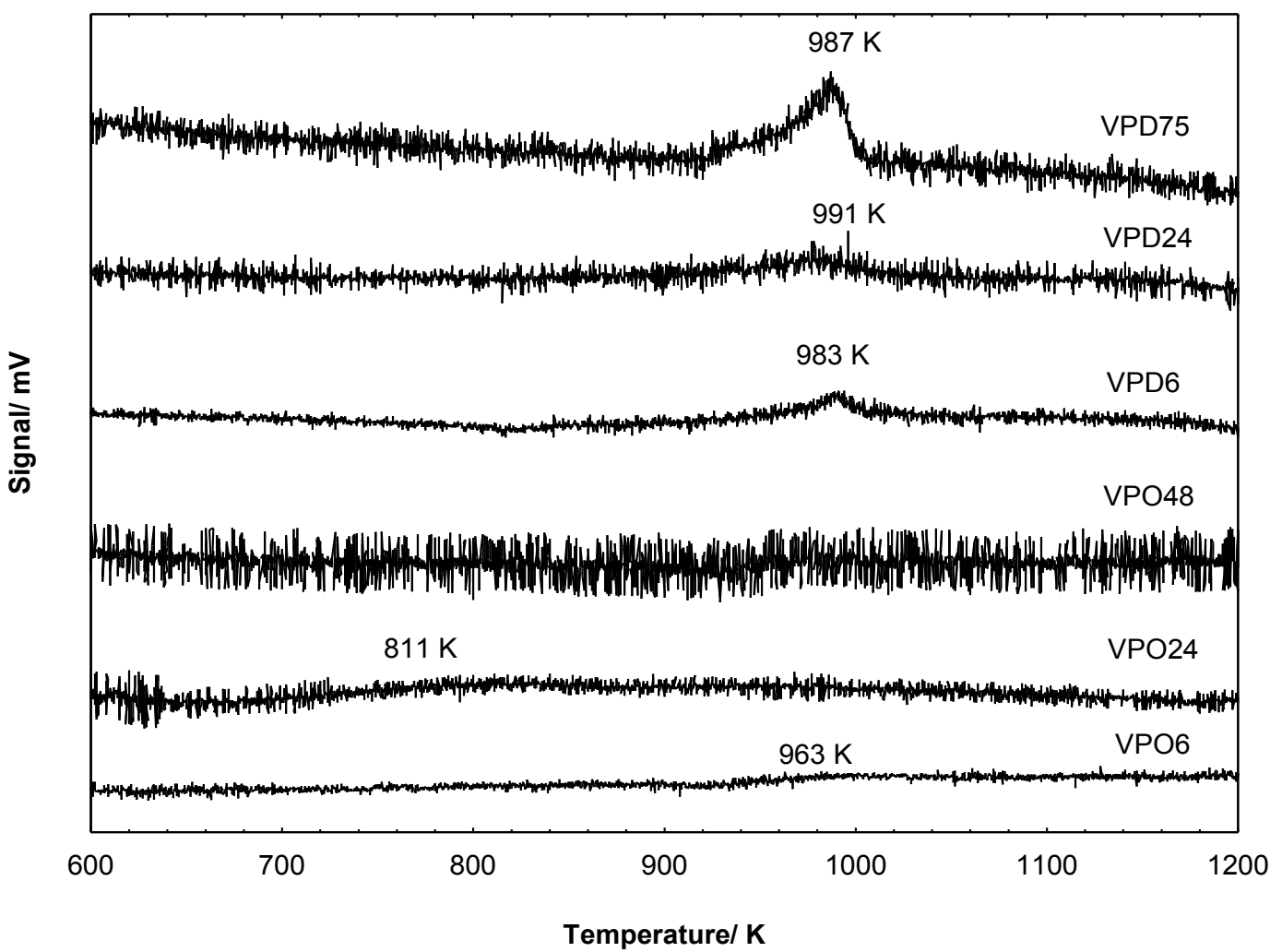

Figure 3. Temperature programmed desorption of $\mathrm{O}_{2}$ from catalysts.

Table 2. $\mathrm{O}_{2}$-TPD data obtained from catalysts.

\begin{tabular}{lllll}
\hline Catalysts & $\mathrm{T}_{\max }(\mathrm{K})$ & $\begin{array}{l}\text { Desorption } \\
\text { Activation } \\
\text { Energy, } \\
\mathrm{E}_{\mathrm{d}} / \mathrm{kJ} \mathrm{mol}^{-1}\end{array}$ & $\begin{array}{l}\text { Oxygen atoms } \\
\text { removed } / \\
\times 10^{-4} \mathrm{~mol} \mathrm{~g}^{-1}\end{array}$ & $\begin{array}{l}\text { Oxygen atoms } \\
\text { removed/ } \\
\times 10^{19} \mathrm{atom} \mathrm{g}^{-1}\end{array}$ \\
\hline VPO6 & 963 & 265.9 & 0.59 & 3.55 \\
VPO24 & 811 & 224.0 & 3.22 & 19.39 \\
VPO48 & - & - & - & - \\
VPD6 & 983 & 271.5 & & 16.86 \\
VPD24 & 991 & 273.7 & 2.80 & 13.25 \\
VPD75 & 987 & 272.6 & 2.20 & 31.92 \\
\hline
\end{tabular}




\section{Temperature-programmed reduction (TPR)}

The amount and nature of the oxygen species of all the catalysts were investigated by temperature-programmed reduction in $\mathrm{H}_{2} / \mathrm{Ar}$ stream $\left(5 \% \mathrm{H}_{2}\right.$ in $\mathrm{Ar}, 1$ bar, $\left.25 \mathrm{~cm}^{3} \mathrm{~min}^{-1}\right)$, using a fresh catalyst and raising the temperature from ambient to $1150 \mathrm{~K}^{2} 10 \mathrm{~K} \mathrm{~min}^{-1}$. Figure 4 shows the profiles of $\mathrm{H}_{2}$-TPR for the catalysts. The total oxygen removed, the derived reduction activation energies and the ratio for oxygen removal from $\mathrm{V}^{5+} / \mathrm{V}^{4+}$ by reduction in $\mathrm{H}_{2} / \mathrm{Ar}$ is summarizes in Table 3. One reduction peak of hydrogen consumption was observed for VPO6 and VPD6 at $1058 \mathrm{~K}$ and $983 \mathrm{~K}$, respectively, which correspond to the reduction of $\mathrm{V}^{4+}$ phases ${ }^{23}$. The results were in agreement with the redox titration results which show only the $\mathrm{V}^{4+}$ phase was present in the VPO6 and VPD6 catalysts. By increasing the calcination duration, the catalysts gave two reduction peaks and the additional peak is assigned to the removal of lattice oxygen from the $\mathrm{V}^{5+}$ phase $\mathrm{e}^{23}$. The TPR profiles show the first reduction peak for VPO24 VPO48, VPD24 and VPD75 which are less prominent compared to the second reduction peak. This is also in agreement with the redox titration where lower percentages of $\mathrm{V}^{5+}$ phase were obtained for these catalysts. Small amount of $\mathrm{V}^{5+}$ phases in the major well crystalline pyrophosphate phase will enhance the catalytic performance of a vanadium phosphate catalyst ${ }^{24}$.

The amount of oxygen removed by $\mathrm{H}_{2}$ is $1.3 \times 10^{21}$ atom $^{-1}$ for VPO6. Interestingly, the total oxygen removed significantly increased to $1.85 \times 10^{21}$ atom $\mathrm{g}^{-1}$ for VPO24 due to the higher oxygen species released associated with $\mathrm{V}^{4+}$ and $\mathrm{V}^{5+}$. However, further calcine to $48 \mathrm{~h}$ reduced the total amount of oxygen removed to $1.63 \times 10^{21}$ atom $\mathrm{g}^{-1}$. For the catalysts synthesized by using VPO method, we suggested that $24 \mathrm{~h}$ of cacination time in an inert environment is the optimum duration to produce a catalyst with better catalytic performance as the VPO24 possesses more labile and highest amount of active $\mathrm{V}^{4+}-\mathrm{O}^{-}$pair for $n$-butane activation $^{24,25}$ and $\mathrm{V}^{5+}-\mathrm{O}^{2-}$ pair for promoting the selectivity to maleic anhydride ${ }^{25-26}$.

Table 3. Total number of oxygen atoms removed from catalysts by reduction in $\mathrm{H}_{2} / \mathrm{Ar}$.

\begin{tabular}{|c|c|c|c|c|}
\hline Catalysts & Peak & $\mathrm{T}_{\max }(\mathrm{K})$ & $\begin{array}{l}\text { Oxygen atoms } \\
\text { removed } / \times 10^{-3} \mathrm{~mol} \mathrm{~g}^{-1}\end{array}$ & $\begin{array}{l}\text { Oxygen atoms } \\
\text { removed } / \times 10^{21} \text { atom } \mathrm{g}^{-1}\end{array}$ \\
\hline VPO6 & 1 & 1058 & 2.15 & 1.3 \\
\hline \multicolumn{3}{|c|}{ Total Oxygen atoms removed } & 2.15 & 1.3 \\
\hline \multirow[t]{2}{*}{ VPO24 } & 1 & 786 & 0.47 & 0.29 \\
\hline & 2 & 1064 & 2.59 & 1.56 \\
\hline \multicolumn{3}{|c|}{ Total Oxygen atoms removed } & 3.06 & 1.85 \\
\hline \multirow[t]{2}{*}{ VPO48 } & 1 & 801 & 0.20 & 0.12 \\
\hline & 2 & 1067 & 2.51 & 1.51 \\
\hline \multicolumn{3}{|c|}{ Total Oxygen atoms removed } & 2.71 & 1.63 \\
\hline VPD6 & 1 & 983 & 2.29 & 1.38 \\
\hline \multicolumn{3}{|c|}{ Total Oxygen atoms removed } & 2.29 & 1.38 \\
\hline \multirow[t]{2}{*}{ VPD24 } & 1 & 908 & 1.14 & 0.69 \\
\hline & 2 & 1038 & 1.63 & 0.98 \\
\hline \multicolumn{3}{|c|}{ Total Oxygen atoms removed } & 2.77 & 1.67 \\
\hline \multirow[t]{2}{*}{ VPD75 } & 1 & 795 & 0.89 & 0.54 \\
\hline & 2 & 1069 & 2.29 & 1.38 \\
\hline \multicolumn{3}{|c|}{ Total Oxygen atoms removed } & 3.18 & 1.92 \\
\hline
\end{tabular}


The amount of oxygen removed from VPD6 is $1.38 \times 10^{21}$ atom $\mathrm{g}^{-1}$. By increasing the duration of calcination of precursor to $24 \mathrm{~h}$, VPD24 catalyst gave a characteristic of two reduction peaks which occurred at 908 and $1038 \mathrm{~K}$, respectively. VPD75 catalyst gave similar characteristic of two peaks with VPD24 catalyst. The first peak occurred at $795 \mathrm{~K}$ and the later peak occurred at $1069 \mathrm{~K}$. The first reduction peak of VPD75 shifted towards lower temperature at $795 \mathrm{~K}$ compared to VPD24 catalyst. The results indicated that VPD75 catalyst possesses higher mobility of $\mathrm{O}^{2-}$ species at low temperature. There are appeared to be a consistency whereby the total amount of oxygen release from the catalysts increased with increasing calcinations time, i.e. $1.67 \times 10^{21}$ atom $\mathrm{g}^{-1}$ and $1.92 \times 10^{21}$ atom g $^{-1}$ for VPD24 and VPD75, respectively. A higher amount of oxygen removed from the VPD75 suggested that this catalyst will give higher activity and selectivity for $n$-butane oxidation compared with the less calcined samples.

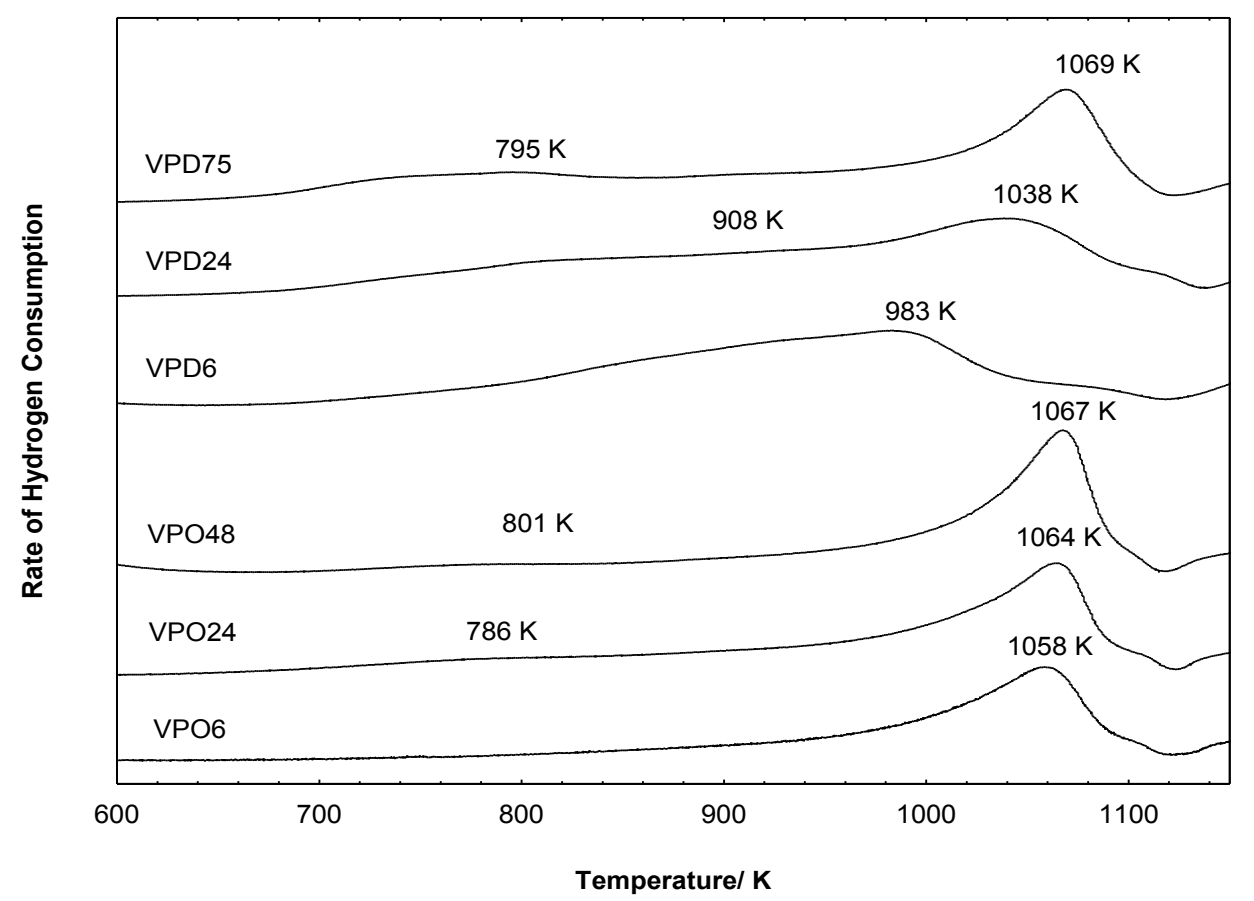

Figure 4. $\mathrm{H}_{2}$-TPR profiles of catalysts.

\section{Conclusions}

1. Increasing the calcination duration of vanadium phosphate catalysts prepared via VPO and VPD method in $\mathrm{N}_{2}$ environment induced the formation of $\mathrm{V}^{5+}$ phase and lowering the surface area of the catalysts. The morphology of all the catalysts is shown to be in rosette shape. However, the shape was getting cracked and lost as the calcination time prolonged.

2. The consumption of $\mathrm{H}_{2}$ in TPR shows that more lattice oxygen can be removed for the $24 \mathrm{~h}$ calcined catalyst which synthesized via VPO method. Besides, the catalysts prepared by using VPD method shows that more amount of oxygen can be removed by $\mathrm{H}_{2}$ after the longer period $\mathrm{N}_{2}$ pretreatment and it is suggested that the longer duration of $\mathrm{N}_{2}$ pretreatment will gave a more active and selective catalyst. 


\section{Acknowledgement}

Financial support from Malaysian Ministry of Science, Technology and Innovation is gratefully acknowledged.

\section{References}

1. Hutchings G J J. Mater. Chem. 2004, 14, 3385.

2. Cavani F, Centi G, Trifirò F and Poli G J. Therm. Anal. 1985, 30, 1241.

3. Centi G, Cavani F and Trifirò F, Selective Oxidation by Heterogeneous Catalysis. Kluwer Academic/Plenum Publishers: New York, 2001, 143.

4. Taufiq-Yap Y H, Looi M H, Waugh K C and Hussein M Z Catal. Lett. 2001, 74, 99.

5. Waugh K C and Taufiq-Yap Y H Catal. Today 2003, 81, 215.

6. Horowitz H S, Blackstone C M, Sleight A W and Teufer G Appl. Catal. 1988, 38, 193.

7. Johnson J W, Johnston D C, Jacobson A J and Brody J F J. Chem. Soc. 1984, 106, 8123.

8. Hutchings G J, Olier R, Sananes M T and Volta J C Stud. Surf. Sci. Catal. 1994, 82, 213.

9. Taufiq-Yap Y H, Goh C K, Waugh K C and Kamiya Y React. Kinet. Catal. L. 2007, 84, 271.

10. Niwa M and Murakami Y J. Catal. 1982, 76, 9.

11. Shen S, Zhou J, Zhang F, Zhou L and Li R Catal. Today 2002, 74, 37.

12. Hodnett B K and Delmon B Appl. Catal. 1984, 9, 203.

13. Cheng W-H and Wang W Appl. Catal. A-Gen. 1997, 156, 57.

14. Poli G, Resta I, Ruggeri O and Trifirò F Appl. Catal. 1981, 1, 395.

15. Centi G, Cavani F and Trifirò F, Selective Oxidation by Heterogeneous Catalysis. Kluwer Academic / Plenum Publishers: New York, 2001, 156.

16. Griesel L, Bartley J K, Wells Richard P K and Hutchings G J J. Mol. Catal. A-Chem. 2004, 220, 113.

17. Taufiq-Yap Y H, Tan K P, Waugh K C, Hussein M Z, Ramli I and Abdul Rahman M B Catal. Lett. 2003, 89, 87.

18. Taufiq-Yap Y H, Kamiya Y and Tan K P J. Nat. Gas Chem. 2006, 15, 297.

19. Taufiq-Yap Y H, Goh C K and Kamiya Y React. Kinet. Catal. L. 2007, 92, 275.

20. Taufiq-Yap Y H and Abdul Ghani A A Chinese J. Catal. 2007, 28, 1037.

21. Kiely C J, Burrows A, Sajip S, Hutchings G J, Sananes M T, Tuel A and Volta J C J. Catal. 1996, 162, 31.

22. Hutchings G J J. Mater. Chem. 2004, 14, 3385.

23. Pierini B T and Lombardo E A Mater. Chem. Phys. 2005, 92, 197.

24. Taufiq-Yap Y H J. Nat. Gas Chem. 2006, 15, 144.

25. Taufiq-Yap Y H, Goh C K, Hutchings G J, Dummer N and Bartley J K J. Mol. Catal. A-Chem. 2006, 260, 24.

26. Sananes M T, Tuel A, Hutchings G J and Volta J C J. Catal. 1997, 166, 388. 


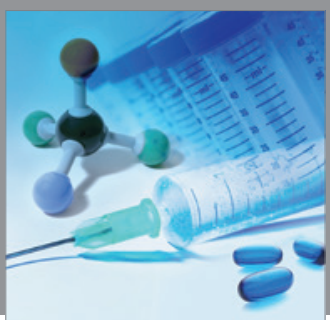

International Journal of

Medicinal Chemistry

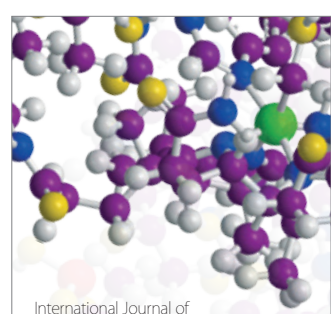

Carbohydrate Chemistry

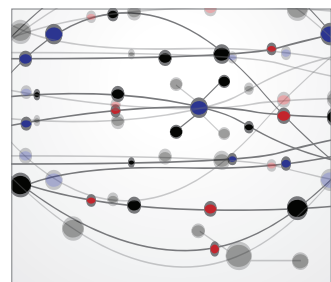

The Scientific World Journal
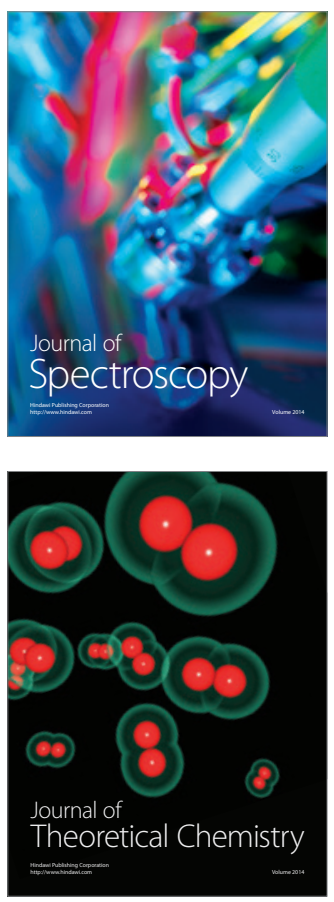
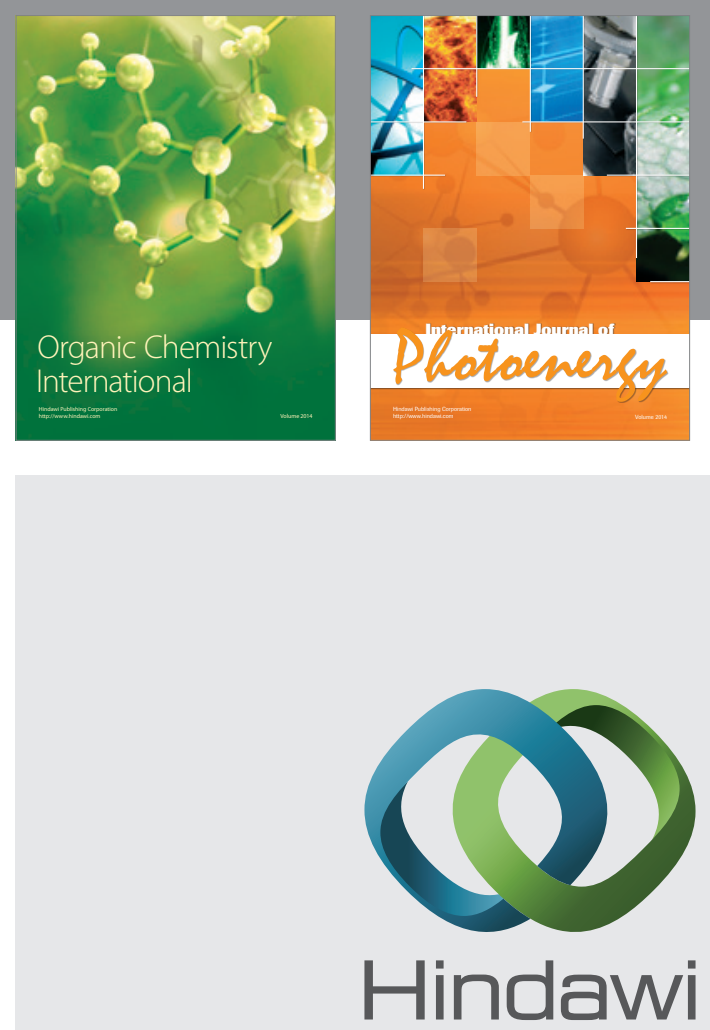

Submit your manuscripts at

http://www.hindawi.com
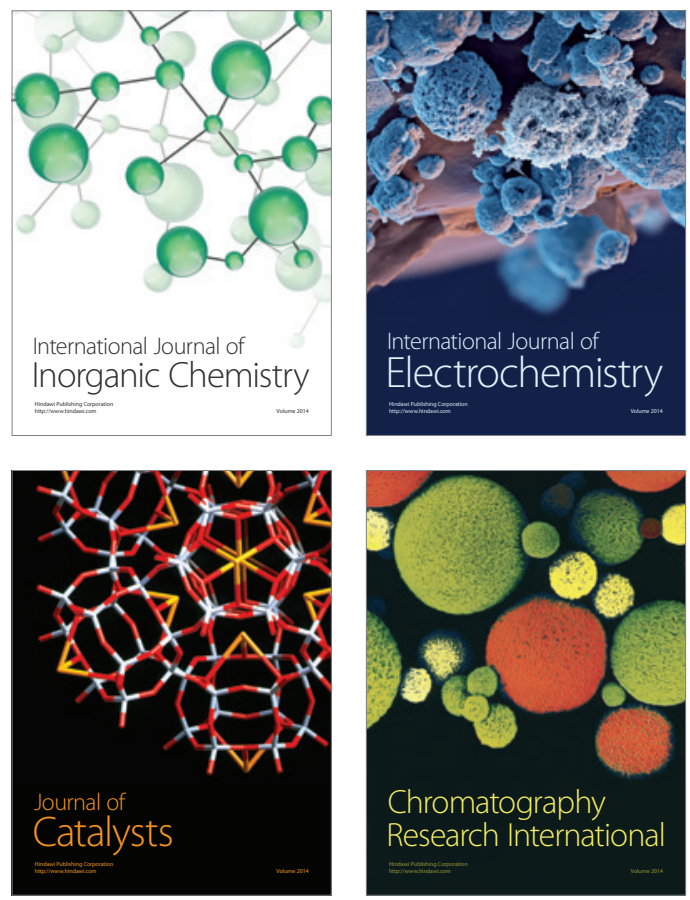
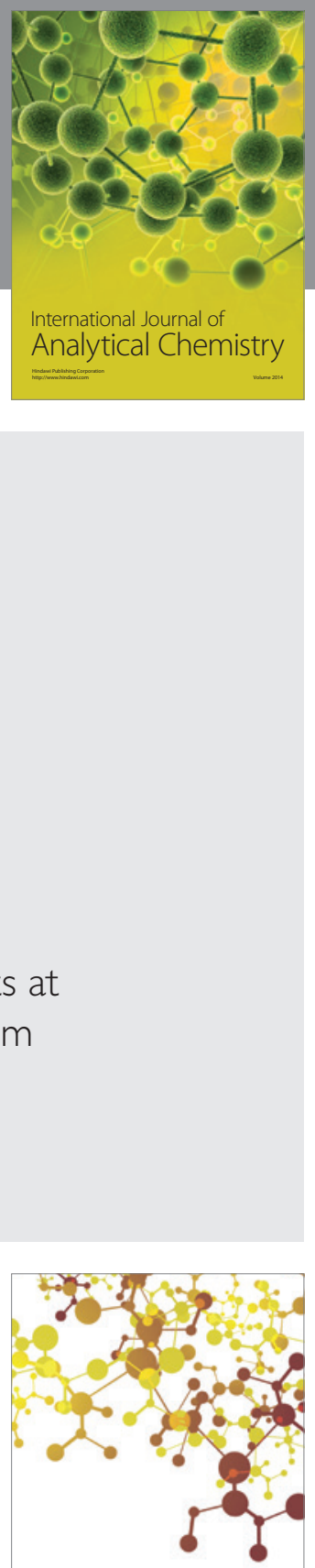

Journal of

Applied Chemistry
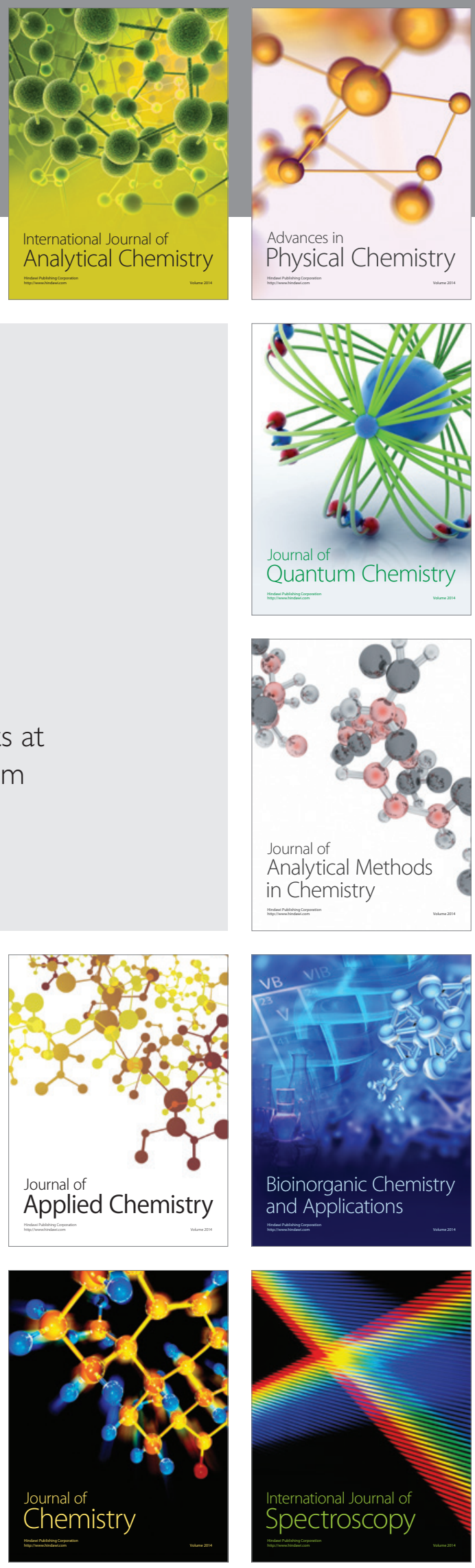